Check for updates

Cite this: RSC Adv., 2018, 8, 4249

Received 9th October 2017 Accepted 15th January 2018

DOI: $10.1039 / c 7 r a 11116 a$

rsc.li/rsc-advances

\section{AS1411 aptamer conjugated gold nanoclusters as a targeted radiosensitizer for megavoltage radiation therapy of 4T1 breast cancer cells}

\author{
Fatemeh Ghahremani, (DD a Daryoush Shahbazi-Gahrouei, ${ }^{* a}$ Amirhosein Kefayat, (D) bc \\ Hasan Motaghi, (D) d Masoud A. Mehrgardi (D)*d \\ and Shaghayegh Haghjooy Javanmard ${ }^{\mathrm{e}}$
}

In the present study, AS1411 aptamer conjugated gold nanoclusters (GNCs) have been introduced as a targeted radiosensitizer for enhancing megavoltage radiation therapy efficacy. GNCs with an ultrasmall gold core and a bovine serum albumin shell (BSA) as a versatile nano-platform were synthesized and conjugated to AS1411 aptamer (Apt-GNCS). Due to nucleolin overexpression in breast cancer cells and high affinity of the AS1411 aptamer to nucleolin, mouse mammary carcinoma cell line (4T1) was selected as the malignant cells and murine fibroblast (L929) was used as a normal cell line. Flow cytometry assessments reveal a significant increase in GNCs uptake by the cancer cells in the presence of the aptamer as the targeting agent. Inductively coupled plasma optical emission spectrometry (ICPOES) measurements demonstrate 4 times more Apt-GNCs uptake by 4T1 cells than the normal cells at a concentration ratio of $1: 40(4 \mu \mathrm{M}$ aptamer and $160 \mu \mathrm{M}$ GNCs at $24 \mathrm{~h}$ incubation). Moreover, the combination of megavoltage radiation therapy and Apt-GNCs as radiosensitizer causes effective cancer cell death and a dose enhancement factor (DEF) of about 2.7 in clonogenic survival assay is obtained.

\section{Introduction}

Breast cancer is a common malignant tumor in women and the second-leading cause of cancer deaths in the world. ${ }^{1}$ While effective methods have been developed for breast cancer diagnosis and treatment during the last few decades it is still one of the main causes of death., ${ }^{2,3}$ In clinical practice, surgery, chemotherapy, radiation therapy (RT) or combinations of these methods are employed for cancer treatment.

RT has been identified as an effective therapeutic modality for many different types of solid tumors ${ }^{4}$ and more than $50 \%$ of patients will need RT during their treatment procedure. ${ }^{5} \mathrm{RT}$ plays a key role in breast cancer treatment, not only for breastconserving surgeries but also after mastectomies. ${ }^{6}$ The main purpose of RT is to deliver a maximum curative dose of radiation to the tumor while sparing surrounding normal tissues. ${ }^{7}$ However, equal radiation beams absorption by tumor and

\footnotetext{
${ }^{a}$ Department of Medical Physics, School of Medicine, Isfahan University of Medical Sciences, Isfahan 81746-73461, Iran. E-mail: shahbazi@med.mui.ac.ir

${ }^{b}$ Cancer Prevention Research Center, Isfahan University of Medical Sciences, Isfahan 81746-73461, Iran

'Department of Oncology, Seyed Al-Shohada Hospital, Isfahan University of Medical Sciences, Isfahan 81746-73461, Iran

${ }^{d}$ Department of Chemistry, University of Isfahan, Isfahan 81746-73441, Iran. E-mail: m.mehrgardi@chem.ui.ac.ir

${ }^{e}$ Department of Physiology, Applied Physiology Research Center, Cardiovascular Research Institute, Isfahan University of Medical Sciences, Isfahan 81746-73461, Iran
}

surrounding healthy tissues is still a great challenge in RT which is caused by attenuation coefficient factor similarity. In order to overcome this challenge and to increase the efficacy of radiation therapy, radiosensitizers application has been recommended.

The radiosensitizing concept was introduced almost 20 years ago by the application of iodine salts and gadolinium complexes for enhancement of radiation therapy efficiency. ${ }^{8,9}$ In recent years, metal nanoparticles have been utilized as the best sensitizers in combination with ionizing radiation. ${ }^{10-12}$ These nanoparticles directly interact with radiation beams and strongly absorb them. Therefore, locally enhance radiation effect when accumulating in tumors. ${ }^{13-15}$ In general, among the radiosensitizers, gold nanoparticles (GNPs) with excellent chemical stability and good biocompatibility ${ }^{\mathbf{1 6}, 17}$ appear as a promising candidate in comparison with other nanoparticles. When X-ray beams collide on GNPs, the energy of radiation beams are absorbed and causes generation of secondary electrons and more subsequent destruction. ${ }^{16,18}$

Ideal radiosensitizers at least must have two properties including efficient tumors accumulation and sufficient renal clearance to minimize toxic side effects. ${ }^{19,20}$ Nanoparticles accumulation in tumors strongly depends on their sizes. ${ }^{21,22}$ In many studies, employed GNPs with large sizes (typically above $50 \mathrm{~nm}$ ); therefore, their trapping by reticuloendothelial system (RES) is probable. This can lead to less delivery of GNPs to the tumor site. ${ }^{23}$ While some previously published manuscripts argued that $50 \mathrm{~nm}$ is the optimum size for the GNPs cellular 
uptake. ${ }^{\mathbf{2 4 2 5}}$ However, more investigations have demonstrated internalization of nanoparticles increases by their size reduction because of their ability for RES escape.,50,26 Therefore, gold nanoclusters (GNCs) with very small sizes can be interesting alternatives to popular GNPs for efficient tumor targeting. The other challenge for the optimum size of nanoparticles is the kidney filtration threshold (almost $5.5 \mathrm{~nm}$ ). ${ }^{27}$ GNCs with very small sizes (under $2 \mathrm{~nm}$ ) can easily excrete via urine, therefore unabsorbed GNCs wouldn't cause toxicity. In addition, not only their small size cause high tumor accumulation but also prevents organ toxicity. GNCs can be easily synthesized in the presence of bovine serum albumin (BSA) as a biocompatible coating ligand. ${ }^{28-30}$

The other challenging factor in radiosensitizer efficacy is tumor targeting ability. For active tumor targeting, various targeting agents including antibodies and aptamers have been employed. ${ }^{31,32}$ Aptamers offer several advantages such as low cost, low immunogenicity, biocompatibility, small size to enable solid tumor penetration and high binding affinity for its target. All of these make aptamers ideal candidates as targeting agents. ${ }^{33}$

AS1411 is an anti-proliferative oligonucleotide which is the first anticancer aptamer to be tested in clinical trials (phase 1 and 2 clinical trials). ${ }^{34,35}$ AS1411 aptamer has widely been utilized as a tumor targeting agent which can be conjugated to wide variety of molecules and nanomaterial. ${ }^{36,37}$ AS1411 aptamer directly binds to nucleolin, ${ }^{38}$ one of the main nucleolus proteins which have significant expression at cancer cells. High tumor selectivity of AS1411 is due to the overexpression of nucleolin in the plasma membrane and cytoplasm of cancer cells compared to normal cells. ${ }^{36}$

The type of radiation also has an effect on treatment efficacy. Although, megavoltage (MV) photon energy is the most popular clinical RT approach right now because of superficial sparing and depth of penetration, many studies have utilized $\mathrm{kV}$ photon energy. ${ }^{16,22,39,40}$ Some theoretical studies mentioned inefficient tissue contrast induction by GNPs at megavoltage radiations range of energy and low RT efficacy enhancement has been predicted for the combination of GNPs with MV photon energy. ${ }^{18,41,42}$ However, the contradictions between theoretical view and experimental results have been evaluated by MonteCarlo simulations. ${ }^{43-45}$ These theoretical studies focused on the macroscopic dose enhancement and dose inhomogeneity have been neglected at nanoscale. ${ }^{44}$

Following an ionizing event in metal radiosensitizers at MV range of energy, secondary electrons will generate. These lead to the generation of a Compton electron with relatively high energy, followed by a shower of Auger electrons with much lower energies. The low energy Auger electrons are responsible for the deposited energy in the radiosensitizers vicinity. ${ }^{\mathbf{4 4}}$ The Auger electron spectrum does not depend on the ionizing radiations energy. Thus, energy deposited in the near of nanoparticles depends weakly on incident photon energy. The number of Auger electrons depends on the atomic layers where ionization occurred. In smaller nanoparticles, the possibility of emission of Auger electrons in the outer atomic layers is more. ${ }^{\mathbf{4 4}}$

To the best our knowledge, there is no report on the application of aptamer modified nanoclusters as a radiosensitizer in the MV photon radiation therapy. In this study, the radiosensitizing capability of AS1411 aptamer conjugated GNCs in MV radiation therapy has been investigated. Apt-GNCs is a very interesting candidate for the enhancement of MV energy in radiation therapy due to its outstanding features including excellent cancer cell internalization and targeting by the aptamer, high radiation absorption, and biocompatibility.

\section{Material and methods}

\subsection{Synthesis and characterization of GNCs}

The synthesis and purification of GNCs have been done based on previously published procedure ${ }^{20}$ with some modifications. Briefly, $5 \mathrm{~mL}$ tetrachloro-auric acid $(10 \mathrm{mM})$ was added to $5 \mathrm{~mL}$ BSA $\left(50 \mathrm{mg} \mathrm{mL}^{-1}\right)$ solution under vigorous stirring. After $2 \mathrm{~min}$, $0.5 \mathrm{~mL} 1 \mathrm{M} \mathrm{NaOH}$ solution was added and the solution was stirred at $37^{\circ} \mathrm{C}$ for $12 \mathrm{~h}$. The solution color changed from light yellow to light orange. For elimination of excess chemicals, the BSA-GNCs suspension was centrifuged at $20000 \mathrm{rpm}$ (Ultra Beckman X100, USA) and the supernatant was removed. Subsequently, the nanoclusters were re-suspended and diluted by PBS and kept in a dark place. For characterization of the GNCs, UV-vis (Shimadzu UV-160, Japan), fluorescence spectra (Shimadzu RF-5301PC Spectrofluorometer) of the nanoclusters were performed. Fourier transform infrared (FTIR) spectra were recorded using a FTIR spectrophotometer (JASCO, Japan) and the dynamic light scattering have been performed using Vasco/ CORDOUAN TECHNOLOGIES (France). Concentrations of the GNCs suspensions were obtained by dissolving in $12.5 \mathrm{M}$ hydrochloric acid and $5 \mathrm{M}$ nitric acid containing solution and measuring the emission of gold ions by using ICP-OES.

\subsection{Cell lines preparation}

4T1 (mouse mammary carcinoma) and L929 (mouse fibroblast) cell lines were purchased from Pasteur Institute (Tehran, Iran). The cells were cultured in RPMI 1640 medium (Sigma, USA) containing $10 \%$ fetal bovine serum (FBS) (Sigma, USA) and 1\% antibiotics mixture containing penicillin (Sigma-Aldrich, Germany) and streptomycin (Sigma-Aldrich, Germany) and incubated in a humidified incubator at $37{ }^{\circ} \mathrm{C}$ in a $5 \% \mathrm{CO}_{2}$ atmosphere.

\subsection{Cell viability assay}

The cytotoxicity was evaluated for 4T1 as cancer cells and L929 as normal cells by MTT assay. $10^{4}$ cells were seeded in 96-well plates and incubated for $24 \mathrm{~h}$ at $37{ }^{\circ} \mathrm{C}$ under $5 \% \mathrm{CO}_{2}$ atmosphere. Different concentrations of GNCs (20, 40, 80 and 160 $\mu \mathrm{M})$ and AS1411 aptamer (1, 2 and $4 \mu \mathrm{M})$ were added to the wells of the treatment group and the final volumes were fixed at 200 $\mu \mathrm{L}$ by RPMI addition. For the control groups, final volumes were also fixed at $200 \mu \mathrm{L}$ by addition of $100 \mu \mathrm{L}$ RPMI to each well. The cells were incubated for one more $24 \mathrm{~h}$ at $37{ }^{\circ} \mathrm{C}$ for GNCs uptake. After $24 \mathrm{~h}$, in vitro cytotoxicity tests were performed using MTT assay. Optical density (OD) was recorded at $590 \mathrm{~nm}$ by micro plate reader (Bio-RAD 680, USA). Cell viability separately was evaluated as percentile of controls for each cell line. 
Also, the MTT assays were performed for the similar contents but cells were irradiated with different doses of megavoltage X-ray radiation. Cells were irradiated with the $6 \mathrm{MV}$ photon X-ray using linear accelerator (Primus, Siemens Ltd, Germany), located in Seyed Al-Shohada Hospital, Isfahan, Iran. Source-to-surface distance (SSD) of $100 \mathrm{~cm}$ and field size of $25 \times 25 \mathrm{~cm}^{2}$ delivered total doses of 2, 4 and 6 Gy with a dose rate of $200 \mathrm{MU} \mathrm{min}{ }^{-1}$.

\subsection{Preparation of AS1411 aptamer conjugated GNCs (Apt- GNCs) and its characterization}

To optimize the experimental conditions, the normal and the cancer cells were incubated with various concentrations of the aptamer $(1,2$, and $4 \mu \mathrm{M})$ and the GNCs $(0,20,40,80$, and 160 $\mu \mathrm{M})$ and their effects on these cells were evaluated by MTT assay (Fig. 2 and 3). Based on results of the MTT assays, $160 \mu \mathrm{M}$ of the GNCs and $4 \mu \mathrm{M}$ of the aptamer as the most effective concentrations were selected for synthesis of the Apt-GNCs (see Section 3.3). Therefore, $160 \mu \mathrm{M}$ the GNCs and $4 \mu \mathrm{M}$ the aptamer were mixed and the solution was stirred at room temperature overnight. Subsequently, centrifuged for $20 \mathrm{~min}$ at $20000 \mathrm{rpm}$ and the supernatant was removed to eliminate unconjugated aptamers. The Apt-GNCs were then re-suspended in PBS for further use. DLS and fluorescence spectroscopy were performed to confirm the conjugation of the aptamer with GNCs.

\subsection{Cellular uptake of GNCs by cancer and normal cells}

Inductively Coupled Plasma Optical Emission Spectrometry (ICP-OES) (Varian Vista-Pro, Australia) measurements were performed to determine cell lines internalized gold concentrations after 6, 12 and $24 \mathrm{~h}$ for obtaining the optimal uptake time. The cells were treated by optimum concentrations of GNCs (160 $\mu \mathrm{M})$ and Apt-GNCs ( $4 \mu \mathrm{M}$ aptamer plus $160 \mu \mathrm{M}$ GNCs). After 3 times washing with PBS, cells were harvested by trypsin (Sigma, USA) and counted. Subsequently, they were centrifuged and dissolved in $3 \mathrm{~mL}$ mixture of $12.5 \mathrm{M}$ hydrochloric acid and $5 \mathrm{M}$ nitric acid with a ratio of 3 to 1 . Finally, the gold ions concentrations were determined using ICP-OES. The cellular gold concentration can be evaluated by dividing the convention to the cells number.

\subsection{Flow cytometry analyses}

The qualitative amount of GNCs and Apt-GNCs uptake by cancer cells was evaluated using flow cytometric analyses. $5 \times$ $10^{5} 4 \mathrm{~T} 1$ cancer cells were incubated with the GNCs and AptGNCs for 24 hours at the same concentration as MTT assay. Cells were detached by trypsin and washed 3 times with PBS. The amount of cellular uptake was evaluated by Flow Cytometer (BD FACS Calibur, USA) and analyzed using Flowing Software (http://flowingsoftware.btk.fi/).

\subsection{Clonogenic cell survival assay}

Clonogenic cell survival assays were performed to evaluate the GNCs and Apt-GNCs efficacy for enhancement of radiation therapy in the presence of different doses of the radiation. The method of calculation was based on the previously reported protocols. ${ }^{46-50}$ In this study, clonogenic assay was used with the option of immediate plating after treatment (IP)..$^{48} 10^{5}$ cells were plated in $35 \mathrm{~mm}^{2}$ dishes and after 24 hours the GNCs and the Apt-GNCs were added and incubated for another $24 \mathrm{~h}$. Afterward, the cells were irradiated with $0,2,4,6$ and 8 Gy X-rays. Immediately after irradiation, the cells were washed with PBS and trypsinized to achieve a single cell suspension. The cells were counted and sufficient cells replated in triplicates $100 \mathrm{~mm}$ Petri dishes for 14-21 days at $37{ }^{\circ} \mathrm{C}$ for survival analysis. Subsequently, the colonies were fixed in methanol, stained with crystal violet $(0.5 \%)$ and counted using a loupe microscope (OLYMPUS, SZXY, Japan). Plating efficiency (PE) was calculated as the ratio of colonies number to seeded cells in the wells with no treatment. The surviving fractions (SF) were calculated as the plating efficiency of the treated group divided to the plating efficiency of the untreated cells. ${ }^{47,48}$ Then, the cell survival curves were obtained using SF and the DEF was obtained from the cell survival curves. The DEF is the ratio of the dose given to the untreated cell that produces $90 \%$ survival divided by the dose given to the cells treated with radiosensitizing agent that produces $90 \%$ survival. ${ }^{16}$

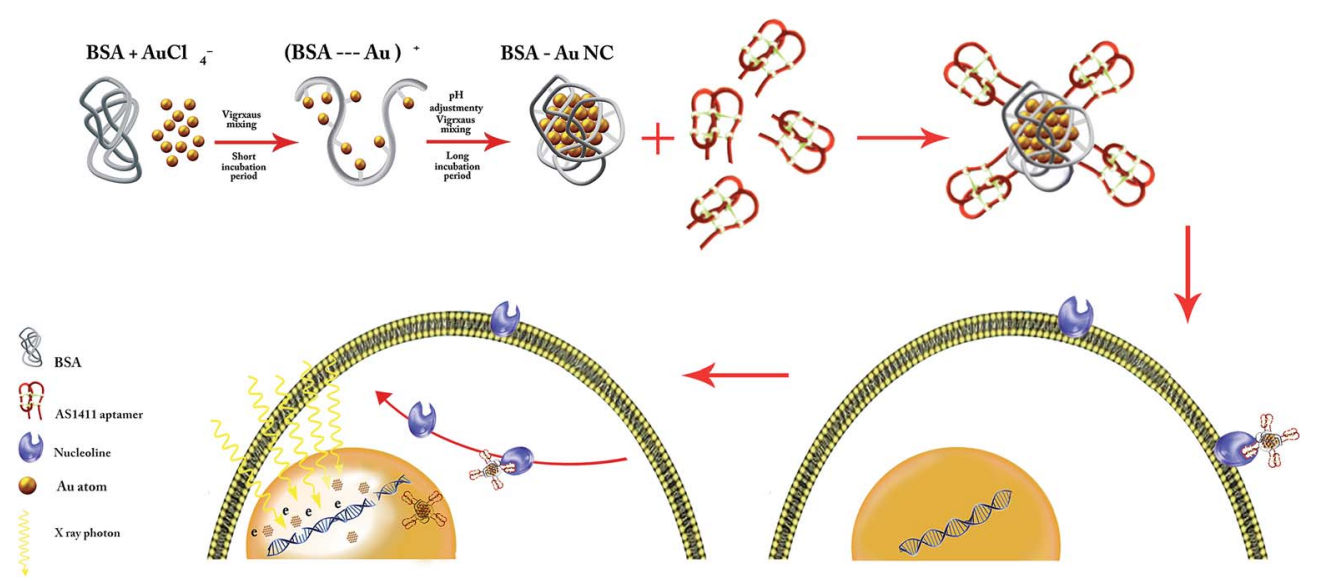

Scheme 1 Schematic illustration of AS1411 aptamer conjugated BSA-GNCs preparation process and the mechanism of its internalization by cancer cells. 


$$
\begin{aligned}
\mathrm{PE}= & (\text { colonies number per dish/seeded cells number per dish }) \\
& \times 100
\end{aligned}
$$

$\mathrm{SF}=(\mathrm{PE}$ of treated sample/PE untreated control $) \times 100$

$\mathrm{DEF}=$ (radiation dose caused 90\% survival at untreated cells/ radiation dose caused $90 \%$ survival at treated cells)

\subsection{Statistical analysis}

Statistical analyses were performed using JMP 11.0 (GraphPad Software, Inc., La Jolla, CA). All data were analyzed by One-Way ANOVA method and $p$-values have been adjusted for multiple comparisons. $P$-values were reported significant for $p<0.05(*: P$ $<0.05, * *: P<0.005$, ns: not significant).

\section{Results and discussion}

The main purpose of the present article is the enhancement of radiotherapy efficacy in the megavoltage energy by using gold nanoclusters as the effective radiosensitizer. For this purpose, the GNCs was synthesized using BSA as the capping agent. Subsequently, GNCs were functionalized by AS1411 aptamer as the targeting agent to target $4 \mathrm{~T} 1$ cancer cells via their membranous nucleolin. Over-expression of nucleolin at the membrane of cancer cells is their cell-specific feature. Apt-GNCs targets the nucleolin by AS1411 aptamer and internalize via a nucleolin shuttling mechanism from cell membrane to the nucleus (Scheme 1). Therefore, GNCs accumulate in cancer cells nucleus and act as radiosensitizers under the radiation beams. Therefore, more secondary electrons generate and DNA damages increases.

\subsection{Synthesis, characterization, and conjugation of GNCs by AS1411 aptamer}

GNCs were synthesized using a previously reported procedure ${ }^{20}$ with slight modifications. UV-vis absorption spectrum of the GNCs (Fig. 1(a)) shows continuous absorption band at the wavelengths under $500 \mathrm{~nm}$ without any obvious peak. Also, Fig. 1(b) shows the fluorescence spectrum with the excitation and emission maximum wavelengths at $292 \mathrm{~nm}$ and $685 \mathrm{~nm}$,
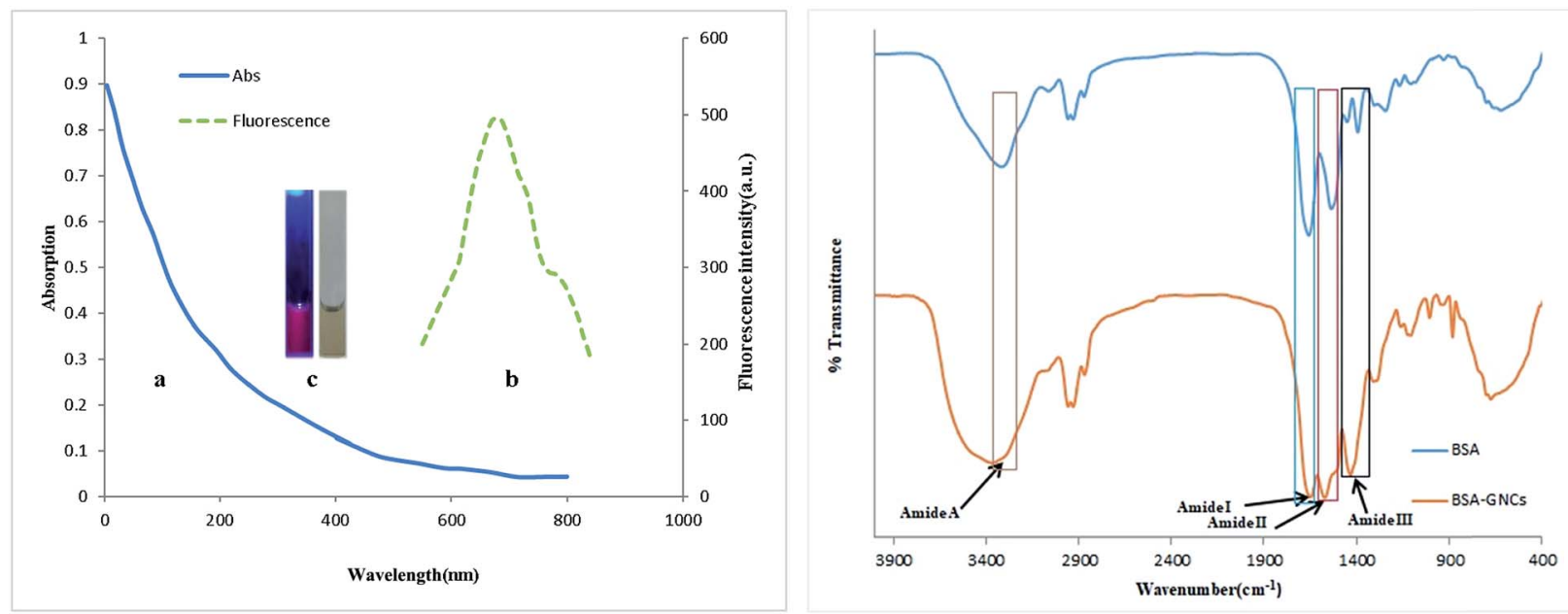

d
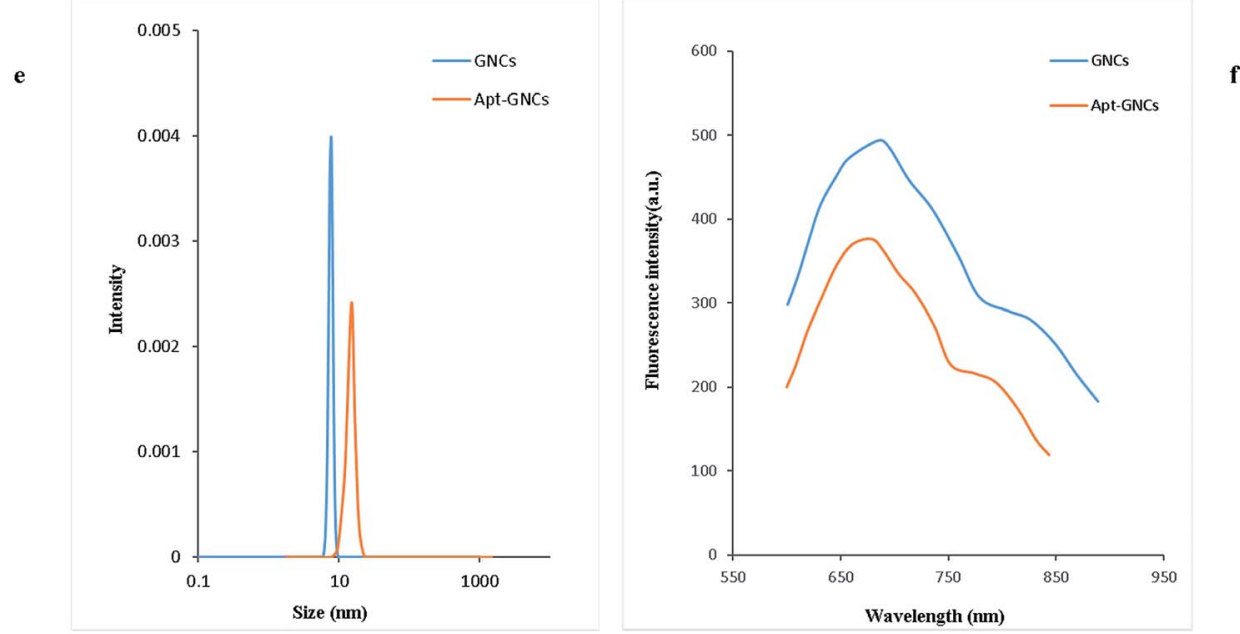

Fig. 1 Synthesis and characterization of the GNCs. (a) UV-vis absorption spectrum. (b) Fluorescence spectrum. (c) Photographs of the GNCs suspension vials under sunlight and ultraviolet lamp. (d) The FTIR spectrum of BSA and BSA-GNCs. (e) Hydrodynamic diameter of the GNCs and the Apt-GNCs. (f) The fluorescence spectra of the GNCs and the Apt-GNCs. 

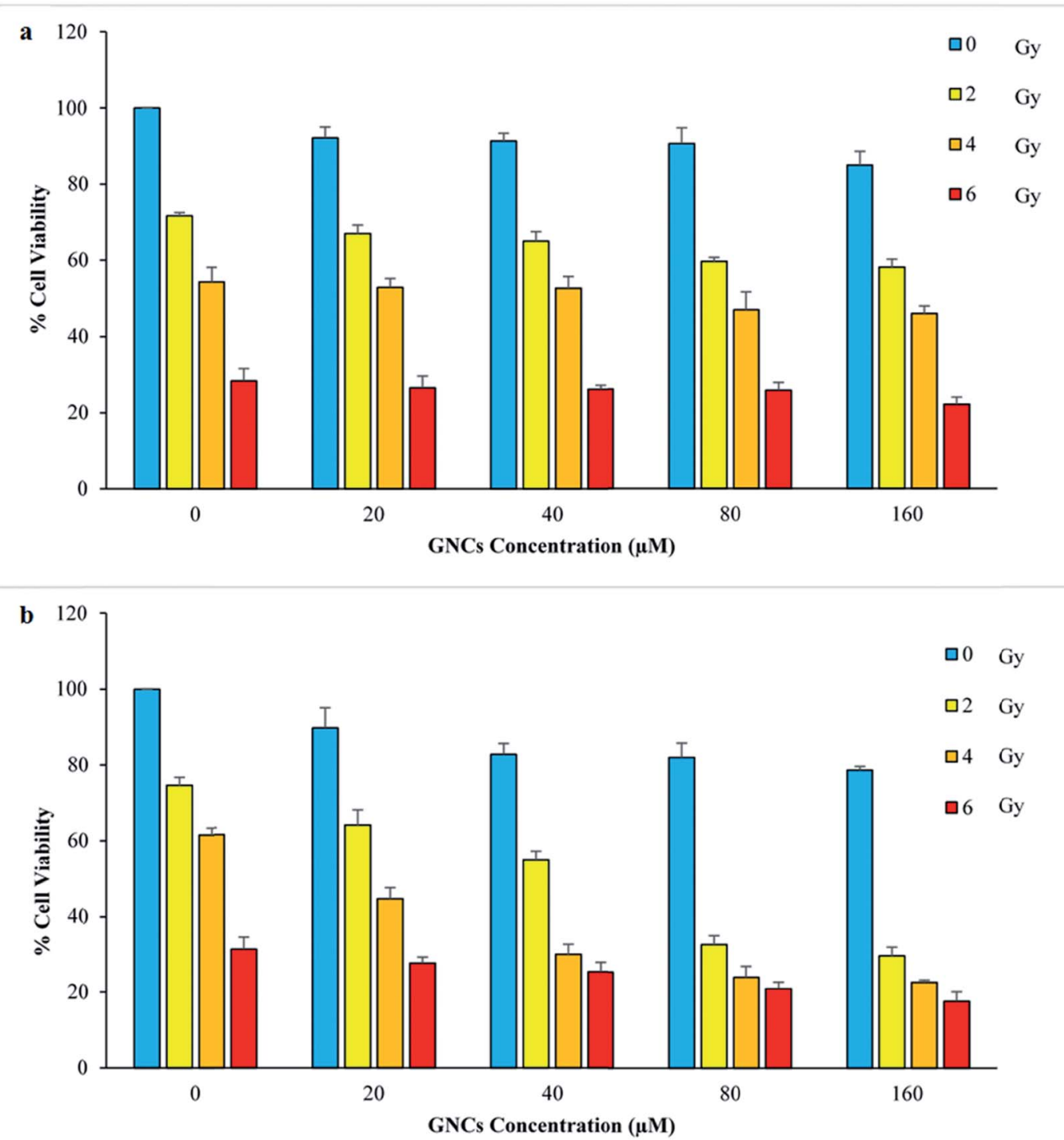

Fig. 2 Effects of different concentrations of the GNCs and radiation therapy doses interaction on cancerous and normal cell line. (a) 4T1 cancer cells. (b) L929 normal fibroblast cells (*: $P \leq 0.05, * *: P \leq 0.005$, ns: not significant).

respectively. The photographs of the GNCs suspension vials under sunlight and ultraviolet lamp are illustrated in Fig. 1(c).

FT-IR spectra of pure BSA solution and the GNCs are compared in Fig. 1(d). Amide bonds which link amino acids show well-defined characteristic peaks that marked as amide I $\left(1653 \mathrm{~cm}^{-1}\right)$, amide II $\left(1530 \mathrm{~cm}^{-1}\right)$, amide III $\left(1240 \mathrm{~cm}^{-1}\right)$ and amide $\mathrm{A}\left(3300 \mathrm{~cm}^{-1}\right)$. Amide band I is the most sensitive band to the secondary structure of proteins and its intensity has been decreased upon the formation of the nanocluster which is in good consistent with previously reported articles. ${ }^{51,52}$

The dynamic light scattering (DLS) experiment was performed after eradication of excess chemicals by centrifuge and four times dilution of the synthesized GNCs suspension using PBS buffer. Fig. 1(e) demonstrates uniform distribution of the GNCs with hydrodynamic size $\sim 7.7 \mathrm{~nm}$ which is in good

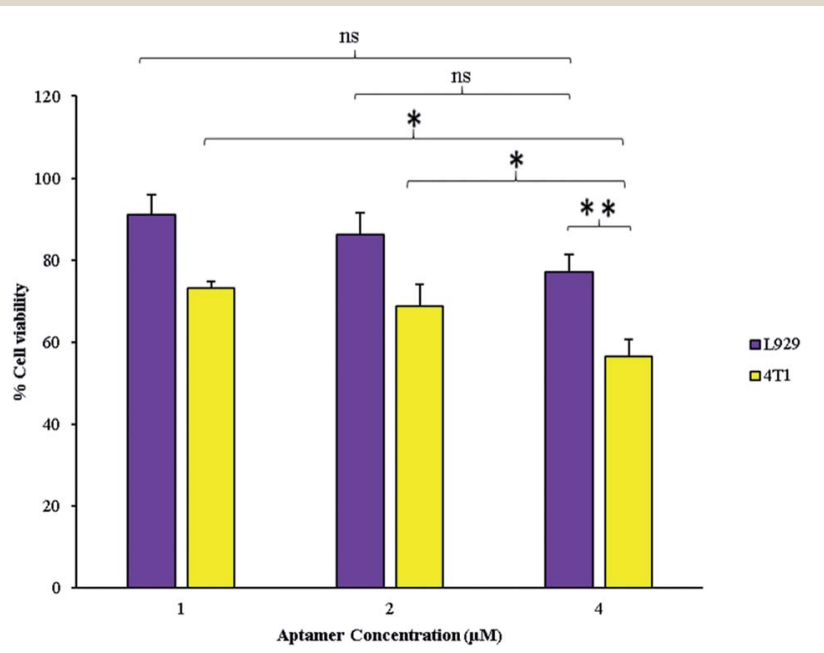

Fig. 3 Effect of different concentrations of AS1411 aptamer on the cancerous and the normal cells (*: $P \leq 0.05$, ns: not significant). 
consistent with previously reported GNCs HD size. ${ }^{20}$ After conjugating of the GNCs with the aptamer under optimum conditions (the optimization for the conjugation of aptamer will be discussed in Section 3.3), the hydrodynamic size shifted from $7.7 \mathrm{~nm}$ to $15.2 \mathrm{~nm}$ (Fig. 1(e)) which confirms the conjugation of the aptamer strands with the GNCs. On the other side, as Fig. 1(f) illustrates, the fluorescence intensity is decreased by conjugation of the aptamer with the GNCs and a $7 \mathrm{~nm}$ blue shift was observed that are consistent with previous studies. ${ }^{52,53}$

\subsection{Assessment of GNCs effect on cancer and normal cells radiation therapy}

The effect of GNCs different concentrations and various radiation doses on cell survivals were evaluated by MTT assay
(Fig. 2). The increase of the GNCs concentrations up to $160 \mu \mathrm{M}$ cause low toxicity for both cell lines (viability percent above $80 \%$ ). As Fig. 2 illustrates, in spite of biocompatibility of the GNCs, enhancement of radiation therapy efficiency was apparent in the GNCs presence. At the same radiation dose, more prominent decrease in cell survival was apparent when the GNCs was utilized. It is interesting that low dose of radiation ( 2 and 4 Gy) with the GNCs ( 80 and $160 \mu \mathrm{M}$ ) exhibits the same destructive effect at cancer cells as high radiation dose (6 Gy) without the GNCs. These can be attributed to the GNCs radiosensitizing effect which was deeply dependent on the GNCs concentration. However, the normal cell line exhibits different behavior which can be explained by difference of the GNCs internalization.
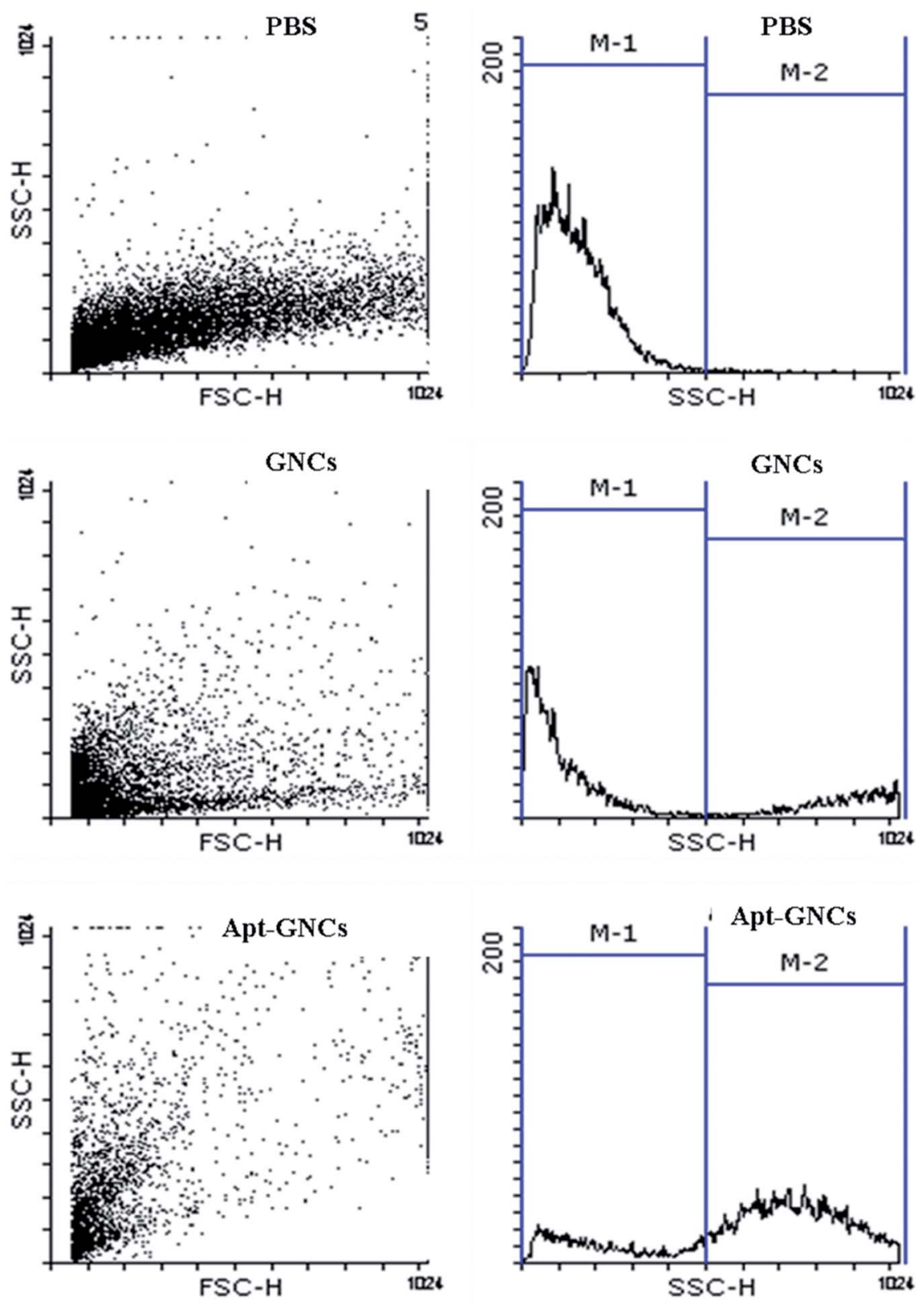

Fig. 4 Qualitative assessment of the GNCs and the Apt-GNCs cancer cells uptake by flow cytometric method. 
Table 1 Flow cytometry assessment of the GNCs and the Apt-GNCs uptake by 4T1 breast cancer cells

\begin{tabular}{lccc}
\hline & PBS & GNCs & Apt-GNCs \\
\hline Percentage of M1 region cells & $98.96 \pm 0.04$ & $61.1 \pm 11.1$ & $20.6 \pm 4.4$ \\
Percentage of M2 region cells & $1.04 \pm 0.04$ & $38.8 \pm 11.1$ & $79.4 \pm 4.4$ \\
SSC mean & $166.79 \pm 15.75$ & $590.81 \pm 122.79$ & $672.97 \pm 38.98$
\end{tabular}

\subsection{Assessment of AS1411 aptamer effect as targeting agent}

GNCs radiosensitizing effect depends on their internalization and accumulation in intended cells. Therefore, decorating by targeting agents for cancer cells targeting can significantly enhance the GNCs radiosensitizing efficacy. The targeting and anti-proliferative effects of AS1411 aptamer on cancer cells with high nucleolin expression profile are well-demonstrated. ${ }^{\mathbf{2 0} 28}$ Therefore, AS1411 aptamer was chosen as specific targeting agent for the GNCs delivery to the breast cancer cells and its anti-proliferative effects. As shown in Fig. 3, AS1411 aptamer has significant anti-proliferative effect on 4T1 cancer cells. Also, it exhibits anti-proliferative effect at all used concentrations. On the other hand, the aptamer effect on the normal cells proliferation isn't significant. At $4 \mu \mathrm{M}$ concentration, the aptamer significantly decreased proliferation of the cancer cells in comparison with the normal cells. Therefore, in this study $4 \mu \mathrm{M}$ aptamer concentration was selected for further experiments and synthesis of the Apt-GNCs.

Efficacy of The GNCs and Apt-GNCs internalization by cancer cells were evaluated by flow cytometry. The best concentrations of the GNCs and the aptamer were conjugated to have a targeted GNCs. GNCs internalization increases cells granularity which causes rise of side scatter intensity (SSC). Enhancement of SSC intensity was observed after $24 \mathrm{~h}$ treatment of the cancer cells by the GNCs which was more prominent at treating by the Apt-GNCs (Fig. 4 and Table 1). The results provide apparent evidence for AS1411 aptamer role at Apt-GNCs uptake by $4 \mathrm{~T} 1$ cancer cells.

\subsection{Quantitative assessment of GNCs uptake by ICP-OES}

ICP-OES results demonstrate Apt-GNCs are much more internalized by the cancer cells compared to the GNCs without aptamer as Fig. 5 illustrates. $24 \mathrm{~h}$ incubation of the cancer cells with GNCs exhibits the same cellular gold uptake as $12 \mathrm{~h} \mathrm{Apt-}$ GNCs incubation. Therefore, conjugation of the GNCs with AS1411 aptamer accelerates the GNCs uptake. Even the GNCs without targeting exhibits more preferences to be internalized by cancer cell rather than normal cells. Nucleolin tropism of AS1411 aptamer causes specific cancer cells targeting. In addition, other researches demonstrated shuttling mechanism of nucleolin to cancer cells nucleus. ${ }^{54-57}$ Therefore, attachment of the Apt-GNCs to the nucleolin not only cause internalization of GNCs but also its deliver to cancer cells nucleus which is the main target of radiation therapy.

\subsection{Assessment of the Apt-GNCs effect on radiation therapy efficiency by MTT and clonogenic cell survival assays}

Effect of the Apt-GNCs and the GNCs on enhancement of radiation therapy efficiency was investigated by MTT assay and clonogenic survival assay. As shown in Fig. 6(a), incubation of the cancer cells with the Apt-GNCs increases the radiation effect at all doses (2, 4, 6 Gy). It's very interesting that 2 Gy radiation therapy of the cancer cells with Apt-GNCs is approximately more efficient than 6 Gy radiation therapy alone. These observations demonstrate radiosensitizing efficacy of the AptGNCs.

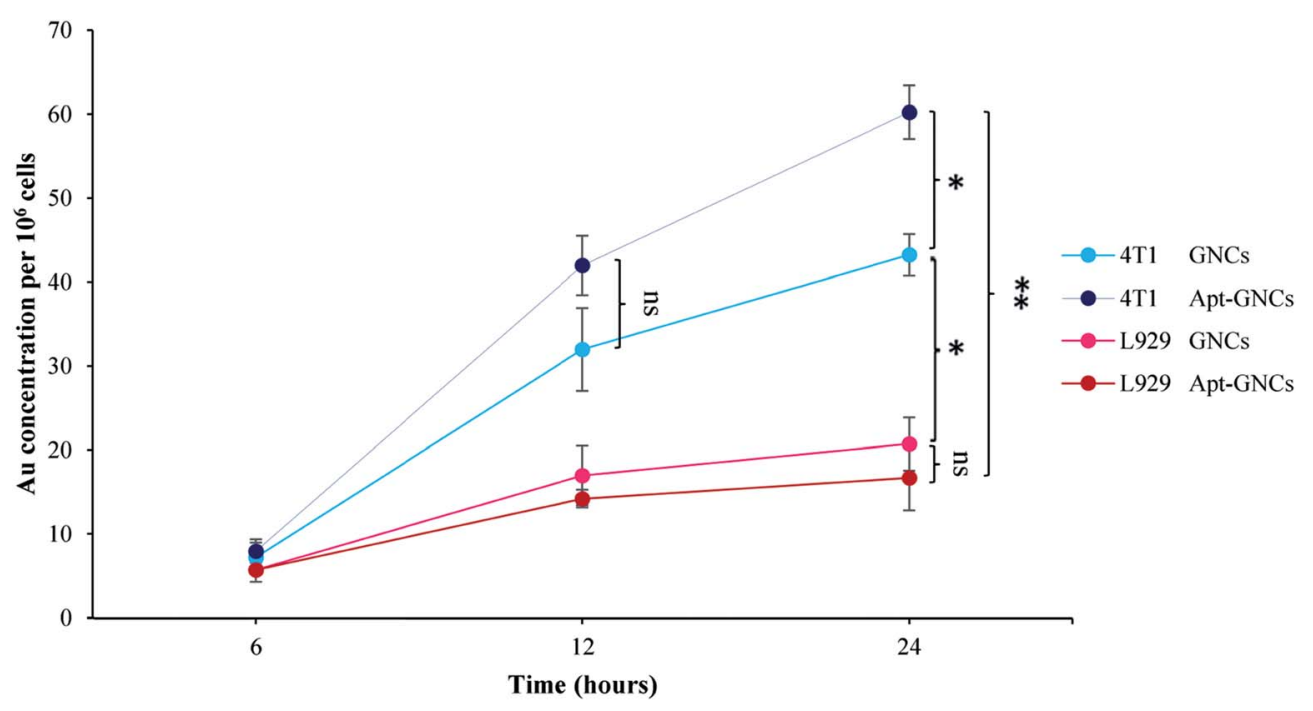

Fig. 5 Quantitative assessment the GNCs and the Apt-GNCs uptake of cancer and normals cells by ICP-OES (*: P $\leq 0.05$, ns: not significant). 
(a)

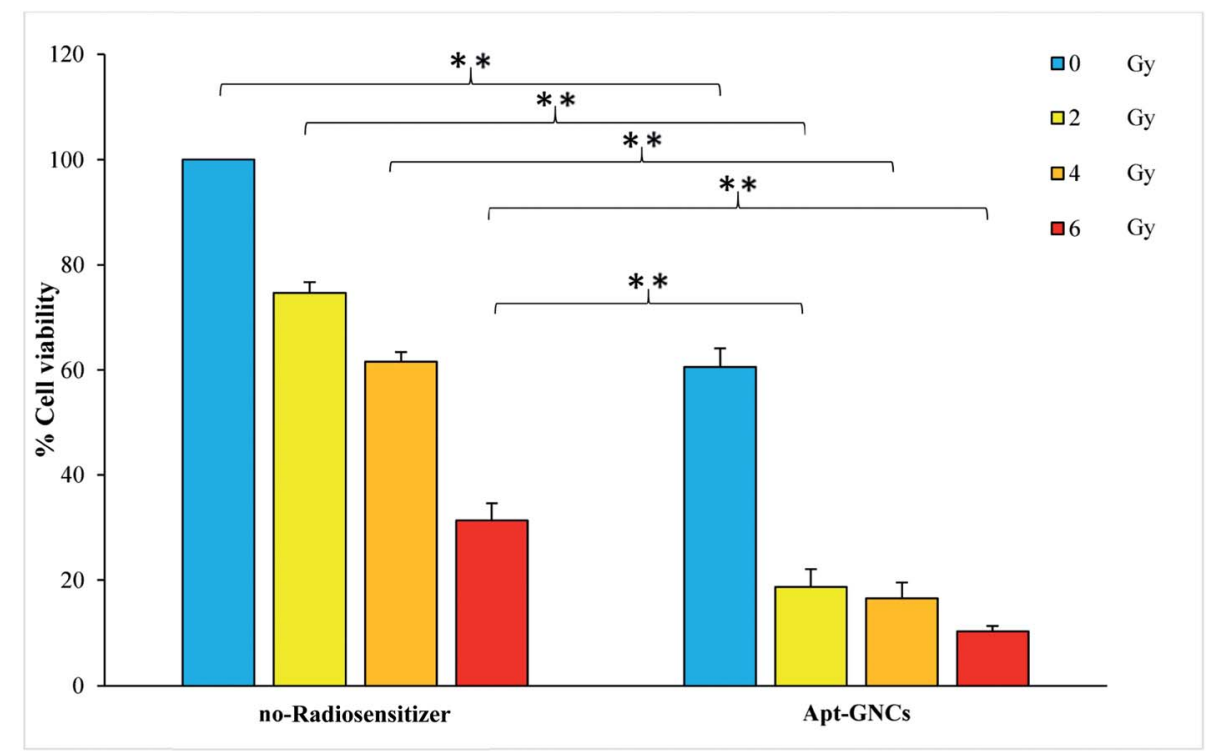

(b)

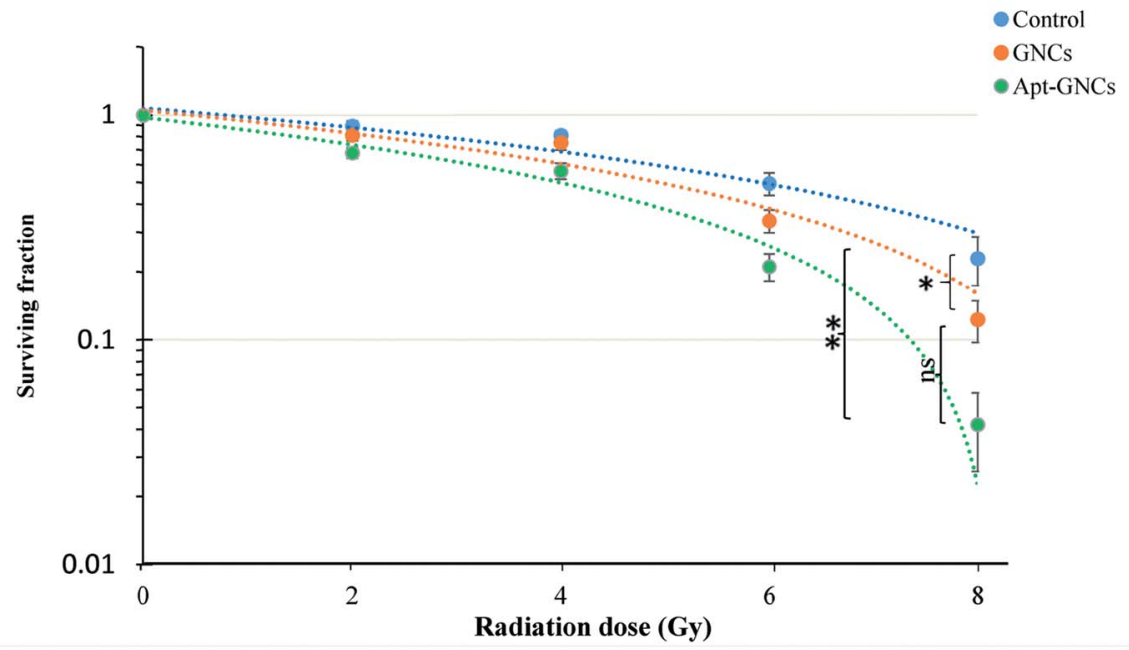

Fig. 6 Effect of the GNCs and the Apt-GNCs on enhancement of radiation therapy efficacy. (a) MTT assay. (b) Clonogenic survival assays (*: P $\leq$ 0.05 , ns: not significant).

In addition, enhancement of radiation therapy efficacy by the GNCs and the Apt-GNCs was assessed by the clonogenic survival assay and obtained DEF. DEF is a quantitative parameter for determining radiation enhancement efficacy. According to many studies, DEF depends on several parameters including the atomic number of radiosensitizer, ${ }^{58}$ type of radiation, ${ }^{\mathbf{1 6 , 2 2 , 3 9 , 4 0 , 4 4}}$ size, design and structure of nanoparticles, ${ }^{\mathbf{4 4 , 5 9 - 6 1}}$ concentration of nanoparticles, ${ }^{\mathbf{1 6}}$ cell line types, ${ }^{\mathbf{4 6 , 6 2}}$ the amount of radiosensitizers uptake by cancer cells which is related to its targeting efficacy and etc. ${ }^{38,63-66} \mathrm{It}$ is obvious that comparison of DEF in various studies is very sophisticated because of the difference in named parameters.

For example, Chattopadhyay et al. ${ }^{50}$ reported 1.6 for DEF, despite the use of HER2 targeting agent and high concentration of GNPs $\left(2.4 \mathrm{mg} \mathrm{mL} \mathrm{m}^{-1}\right)$. This may be because of the nonsufficient size $(30 \mathrm{~nm})$ of nanoparticles and the type of the utilized radiation $\left(100 \mathrm{kV}_{\mathrm{p}}\right)$. Many other studies ${ }^{\mathbf{6 0 , 6 1 , 6 3 , 6 4 , 6 7 - 6 9}}$ have focused on different properties of nanoparticle for the optimization of radiosensitizing effectiveness. Another research ${ }^{70}$ demonstrates that ultra-small GNPs with PEG modification leads to DEF of 2.8. In this study, no targeting agent is used, and the radiation beam is $220 \mathrm{kV}_{\mathrm{p}} \mathrm{X}$-ray. DEF of 2.9 and 3.7 have been reported by Rahman et al. ${ }^{16}$ for $1.9 \mathrm{~nm}$ GNPs in the presence of $6 \mathrm{MeV}$ and $12 \mathrm{MeV}$ radiation, respectively. Also, citrate gold nanoparticle with $14.8 \mathrm{~nm}$ size and $15 \mu \mathrm{g} \mathrm{mL}{ }^{-1}$ concentration is used and in the presence of MV radiation for Hela cell line leads to DEF of 2.88. It's worthy to note that employing smaller gold nanoparticles can cause significant increase of radiation efficacy and the obtained DEFs. Although, Wang et al. ${ }^{69}$ used glucose targeted GNPs with small size $(13 \mathrm{~nm})$ and 6 MV radiation, low concentration of the GNPs (20 nM) leads to DEF as much as 1.5. This demonstrates that the concentration of GNPs is important, too. Therefore, we tried to employ ultra- 
small GNCs with high concentration. In addition, for increasing the GNCs concentration at the inner of the cancer cells, the GNCs were targeted by the aptamer.

The cell survival curves were obtained as a fraction of cells ability to reproduce in the presence of the GNCs or the AptGNCs. As shown in Fig. 6(b), an obvious enhancement in the radiation therapy efficiency is observed for the cells treated by the GNCs and especially the Apt-GNCs.

In this study, the acquired DEF factor for the GNCs and the Apt-GNCs is 1.3 and 2.7, respectively. Radiation therapy efficacy enhancement of the Apt-GNCs may be attributed to targeting efficacy of the aptamer which apparently increases the GNCs uptake by the cancer cells and subsequently, enhances radiation beams and their secondary products induced DNA damage.

\section{Conclusion}

Radiation therapy is a promising therapeutic and palliative approach for cancer. One of the main challenge for cancer radiation therapy is normal tissue damage at treatment field which limits radiation dose. Therefore, cancer cells specific radiosensitizers are gaining too many attentions for selectively enhancement radiation effects at cancer cells. In the present study, ultra-small BSA capped gold nanoclusters targeted by AS1411 aptamer are introduced. Gold nanoclusters are unrivaled radiosensitizing candidate for megavoltage radiotherapy. On the other hand, their conjugation with AS1411 aptamer as breast cancer cells targeting agent significantly enhances their efficacy which is obviously related to increase of their uptake. This work is a part of PhD thesis and financially supported (No. 395468 and No. 195113) by the Isfahan University of Medical Sciences, Isfahan, Iran.

\section{Conflicts of interest}

There are no conflicts to declare.

\section{Acknowledgements}

The study was carried out at School of Medicine, Isfahan University of Medical Sciences and Department of Chemistry, University of Isfahan, Iran. The authors would like to express their sincere thanks to Mr Alireza Assadian \& Miss Zohre Valiniya for their graphical ideas in designing the scheme.

\section{References}

1 M. Cianfrocca and W. J. Gradishar, Oncologist, 2005, 10, 766779.

2 J. A. O'shaughnessy, R. S. Clark, J. L. Blum, R. G. Mennel, D. Snyder, Z. Ye, A. M. Liepa, A. S. Melemed and D. A. Yardley, Clin. Breast Cancer, 2005, 6, 143-149.

3 M. Lacroix, Endocr.-Relat. Cancer, 2006, 13, 1033-1067.

4 L. R. Prosnitz, I. S. Goldenberg, R. A. Packard, M. B. Levene, J. Harris, S. Hellman, P. E. Wallner, L. W. Brady, C. M. Mansfield and S. Kramer, Cancer, 1977, 39, 917-923.
5 X.-D. Zhang, Z. Luo, J. Chen, S. Song, X. Yuan, X. Shen, H. Wang, Y. Sun, K. Gao and L. Zhang, Sci. Rep., 2015, 5, 1-7.

6 F. Sedlmayer, M.-L. Sautter-Bihl, W. Budach, J. Dunst, G. Fastner, P. Feyer, R. Fietkau, W. Haase, W. Harms and R. Souchon, Strahlenther. Onkol., 2013, 189, 825-833.

7 P. Mayles, A. Nahum and J.-C. Rosenwald, Handbook of radiotherapy physics: theory and practice, CRC Press, 2007.

8 D. Schardt, T. Elsässer and D. Schulz-Ertner, Rev. Mod. Phys., 2010, 82, 383-425.

9 R. Cao-Milán and L. M. Liz-Marzán, Expert Opin. Drug Delivery, 2014, 11, 741-752.

10 E. Porcel, S. Liehn, H. Remita, N. Usami, K. Kobayashi, Y. Furusawa, C. Le Sech and S. Lacombe, Nanotechnology, 2010, 21, 085103.

11 E. Porcel, O. Tillement, F. Lux, P. Mowat, N. Usami, K. Kobayashi, Y. Furusawa, C. Le Sech, S. Li and S. Lacombe, Nanomedicine: Nanotechnology, Biology and Medicine, 2014, 10, 1601-1608.

12 P. Liu, Z. Huang, Z. Chen, R. Xu, H. Wu, F. Zang, C. Wang and N. Gu, Nanoscale, 2013, 5, 11829-11836.

13 J. M. Brown and P. Workman, Radiat. Res., 1980, 82, 171-190. 14 K. T. Butterworth, S. J. McMahon, F. J. Currell and K. M. Prise, Nanoscale, 2012, 4, 4830-4838.

15 H. Ali and J. E. Van Lier, Chem. Rev., 1999, 99, 2379-2450.

16 W. N. Rahman, N. Bishara, T. Ackerly, C. F. He, P. Jackson, C. Wong, R. Davidson and M. Geso, Nanomedicine: Nanotechnology, Biology and Medicine, 2009, 5, 136-142.

17 A. Espinosa, A. K. Silva, A. Sánchez-Iglesias, M. Grzelczak, C. Péchoux, K. Desboeufs, L. M. Liz-Marzán and C. Wilhelm, Adv. Healthcare Mater., 2016, 5, 1040-1048.

18 D. B. Chithrani, S. Jelveh, F. Jalali, M. van Prooijen, C. Allen, R. G. Bristow, R. P. Hill and D. A. Jaffray, Radiat. Res., 2010, 173, 719-728.

19 X. D. Zhang, Z. Luo, J. Chen, X. Shen, S. Song, Y. Sun, S. Fan, F. Fan, D. T. Leong and J. Xie, Adv. Mater., 2014, 26, 45654568.

20 X. D. Zhang, J. Chen, Z. Luo, D. Wu, X. Shen, S. S. Song, Y. M. Sun, P. X. Liu, J. Zhao and S. Huo, Adv. Healthcare Mater., 2014, 3, 133-141.

21 B. D. Chithrani, A. A. Ghazani and W. C. Chan, Nano Lett., 2006, 6, 662-668.

22 W. Jiang, B. Y. Kim, J. T. Rutka and W. C. Chan, Nat. Nanotechnol., 2008, 3, 145-150.

23 G. Zhang, Z. Yang, W. Lu, R. Zhang, Q. Huang, M. Tian, L. Li, D. Liang and C. Li, Biomaterials, 2009, 30, 1928-1936.

24 S. Huo, H. Ma, K. Huang, J. Liu, T. Wei, S. Jin, J. Zhang, S. He and X.-J. Liang, Cancer Res., 2013, 73, 319-330.

25 C. H. J. Choi, C. A. Alabi, P. Webster and M. E. Davis, Proc. Natl. Acad. Sci. U. S. A., 2010, 107, 1235-1240.

26 X. Ma, Y. Wu, S. Jin, Y. Tian, X. Zhang, Y. Zhao, L. Yu and X.-J. Liang, ACS Nano, 2011, 5, 8629-8639.

27 H. S. Choi, W. Liu, P. Misra, E. Tanaka, J. P. Zimmer, B. I. Ipe, M. G. Bawendi and J. V. Frangioni, Nat. Biotechnol., 2007, 25, 1165-1170. 
28 Y. Zhang, F. Zheng, T. Yang, W. Zhou, Y. Liu, N. Man, L. Zhang, N. Jin, Q. Dou and Y. Zhang, Nat. Mater., 2012, 11, 817-826.

29 J. Yu, S. A. Patel and R. M. Dickson, Angew. Chem., 2007, 119, 2074-2076.

30 Y. Yu, B. Y. Mok, X. J. Loh and Y. N. Tan, Adv. Healthcare Mater., 2016, 5, 1844-1859.

31 B. Haley and E. Frenkel, Urol. Oncol.: Semin. Orig. Invest., 2008, 26, 57-64.

32 F. X. Gu, R. Karnik, A. Z. Wang, F. Alexis, E. LevyNissenbaum, S. Hong, R. S. Langer and O. C. Farokhzad, Nano today, 2007, 2, 14-21.

33 C. R. Ireson and L. R. Kelland, Mol. Cancer Ther., 2006, 5, 2957-2962.

34 F. Mongelard and P. Bouvet, Curr. Opin. Mol. Ther., 2010, 12, 107-114.

35 L. L. Li, Q. Yin, J. Cheng and Y. Lu, Adv. Healthcare Mater., 2012, 1, 567-572.

36 S. Soundararajan, W. Chen, E. K. Spicer, N. Courtenay-Luck and D. J. Fernandes, Cancer Res., 2008, 68, 2358-2365.

37 E. Reyes-Reyes, F. R. Šalipur, M. Shams, M. K. Forsthoefel and P. J. Bates, Mol. Oncol., 2015, 9, 1392-1405.

38 T. Watanabe, K. Hirano, A. Takahashi, K. Yamaguchi, M. Beppu, H. Fujiki and M. Suganuma, Biol. Pharm. Bull., 2010, 33, 796-803.

39 J. F. Hainfeld, D. N. Slatkin and H. M. Smilowitz, Phys. Med. Biol., 2004, 49, N309.

40 A. Saberi, D. Shahbazi-Gahrouei, M. Abbasian, M. Fesharaki, A. Baharlouei and Z. Arab-Bafrani, Int. J. Radiat. Biol., 2017, 93, 315-323.

41 A. Alkhatib, Y. Watanabe and J. H. Broadhurst, Med. Phys., 2009, 36, 3543-3548.

42 S. Jain, D. Hirst and J. O'sullivan, Br. J. Radiol., 2012, 85, 101113.

43 S. J. McMahon, W. B. Hyland, M. F. Muir, J. A. Coulter, S. Jain, K. T. Butterworth, G. Schettino, G. R. Dickson, A. R. Hounsell and J. M. O'Sullivan, Radiother. Oncol., 2011, 100, 412-416.

44 S. J. McMahon, W. B. Hyland, M. F. Muir, J. A. Coulter, S. Jain, K. T. Butterworth, G. Schettino, G. R. Dickson, A. R. Hounsell and J. M. O'sullivan, Sci. Rep., 2011, 1, 1-9.

45 F. Xiao, Y. Zheng, P. Cloutier, Y. He, D. Hunting and L. Sanche, Nanotechnology, 2011, 22, 465101.

46 S. Jain, J. A. Coulter, A. R. Hounsell, K. T. Butterworth, S. J. McMahon, W. B. Hyland, M. F. Muir, G. R. Dickson, K. M. Prise and F. J. Currell, Int. J. Radiat. Oncol., Biol., Phys., 2011, 79, 531-539.

47 A. Munshi, M. Hobbs and R. E. Meyn, Chemosensitivity, 2005, 1, 21-28.

48 N. A. Franken, H. M. Rodermond, J. Stap, J. Haveman and C. Van Bree, Nat. Protoc., 2006, 1, 2315-2319.
49 L. Cui, K. Tse, P. Zahedi, S. M. Harding, G. Zafarana, D. A. Jaffray, R. G. Bristow and C. Allen, Radiat. Res., 2014, 182, 475-488.

50 N. Chattopadhyay, Z. Cai, Y. L. Kwon, E. Lechtman, J.-P. Pignol and R. M. Reilly, Breast Cancer Res. Treat., 2013, 137, 81-91.

51 P. L. Xavier, K. Chaudhari, P. K. Verma, S. K. Pal and T. Pradeep, Nanoscale, 2010, 2, 2769-2776.

52 S. Govindaraju, S. R. Ankireddy, B. Viswanath, J. Kim and K. Yun, Sci. Rep., 2017, 7, 1-12.

53 H. Li, Y. Guo, L. Xiao and B. Chen, Analyst, 2014, 139, 285289.

54 J. Wu, C. Song, C. Jiang, X. Shen, Q. Qiao and Y. Hu, Mol. Pharmaceutics, 2013, 10, 3555-3563.

55 M. Sader, J. Courty and D. Destouches, J. Nanomed. Nanotechnol., 2015, 6, 2.

56 E. M. Reyes-Reyes, Y. Teng and P. J. Bates, Cancer Res., 2010, 8617-8629.

57 D. H. M. Dam, J. H. Lee, P. N. Sisco, D. T. Co, M. Zhang, M. R. Wasielewski and T. W. Odom, ACS Nano, 2012, 6, 3318-3326.

58 J. Coulter, W. Hyland, J. Nicol and F. Currell, Clin. Oncol., 2013, 25, 593-603.

59 J. C. Roeske, L. Nuñez, M. Hoggarth, E. Labay and R. R. Weichselbaum, Technol. Cancer Res. Treat., 2007, 6, 395-401.

60 X.-D. Zhang, D. Wu, X. Shen, J. Chen, Y.-M. Sun, P.-X. Liu and X.-J. Liang, Biomaterials, 2012, 33, 6408-6419.

61 D. Wu, X.-D. Zhang, P.-X. Liu, L.-A. Zhang, F.-Y. Fan and M.-L. Guo, Curr. Nanosci., 2011, 7, 110-118.

62 K. Butterworth, J. Coulter, S. Jain, J. Forker, S. McMahon, G. Schettino, K. Prise, F. Currell and D. Hirst, Nanotechnology, 2010, 21, 1-18.

63 S. D. Perrault, C. Walkey, T. Jennings, H. C. Fischer and W. C. Chan, Nano Lett., 2009, 9, 1909-1915.

64 B. D. Chithrani, A. A. Ghazani and W. C. Chan, Nano Lett., 2006, 6, 662-668.

65 Y. Liu, W. Chen, P. Zhang, X. Jin, X. Liu, P. Li, F. Li, H. Zhang, G. Zou and Q. Li, Radiother. Oncol., 2016, 119, 544-551.

66 H. Maeda, Adv. Enzyme Regul., 2001, 41, 189-207.

67 S. Jain, J. A. Coulter, K. T. Butterworth, A. R. Hounsell, S. J. McMahon, W. B. Hyland, M. F. Muir, G. R. Dickson, K. M. Prise and F. J. Currell, Radiother. Oncol., 2014, 110, 342-347.

68 J. A. Coulter, S. Jain, K. T. Butterworth, L. E. Taggart, G. R. Dickson, S. J. McMahon, W. B. Hyland, M. F. Muir, C. Trainor and A. R. Hounsell, Int. J. Nanomed., 2012, 7, 2673.

69 C. Wang, X. Li, Y. Wang, Z. Liu, L. Fu and L. Hu, J. Nanopart. Res., 2013, 15, 1642.

70 R. Kumar, H. Korideck, W. Ngwa, R. I. Berbeco, G. M. Makrigiorgos and S. Sridhar, Transl. Cancer Res., 2013, 2, 1-18. 